\title{
Nuevas perspectivas en la formación de maestros para generar nuevos enfoques educativos. Educación Visual y Plástica en las aulas de primaria.
}

Isabel Requejo irequejo@ub.edu

Begonya Samit bsamit@ub.edu

Departamento de Educación Visual y Plástica. Facultad de Formación del Profesorado.

Universidad de Barcelona, España

Reference

Requejo, Isabel; Samit, Begonya; (2012) "Nuevas perspectivas en la formación de maestros para generar nuevos enfoques educativos. Educación Visual y Plástica en las aulas de primaria.", p. 321-326 . In: Barbosa, Helena; Quental Joana [Eds]. Proceedings of the 2nd International Conference of Art, Illustration and Visual Culture in Infant and Primary Education. São Paulo: Blucher, 2015. ISSN 2318-695X, ISBN: 978-989-98185-O-7 DOI 10.5151/edupro-aivcipe-61

Plantear nuevos enfoques en la educación artística pasa, inicialmente, por detectar de qué manera se produce actualmente esta enseñanza en las aulas de primaria, y por constatar que, en la gran mayoría de los casos, sigue estrechamente relacionada a métodos tradicionales.

Defendemos pues que un paso imprescindible para la mejora metodológica de la enseñanza artística es incentivar la formación permanente del profesorado de primaria hacia contenidos propios de esta área de conocimiento, la Educación Visual y Plástica, carente de especialización en España.

Para plantear esta iniciativa, la pregunta que creemos necesaria formular es ¿Qué tipo de educación queremos para los niños y niñas de hoy? y por tanto ¿De qué manera deseamos potenciar la educación artística en la escuela? educación visual y plástica, formación del profesorado, educación primaria.

\section{Abstract}

Suggesting a new focus in art education first demands an examination of the way its teaching is being conducted in elementary school and establish that, in the large majority of cases, art education remains closely related to traditional methods.

We defend that one necessary first step to improve the methodology of art education is to provide a stimulus to the initial and continuous training of elementary teachers to allow for learning in this field who would otherwise be without this specialization in Spain.

The communication poses two key questions: What kind of art education do we want for our boys and girls? And secondly, In what way do we want to increase art education at school?

\section{Introducción}

La educación artística ha vivido en un círculo vicioso de difícil apertura (...) gestado por la falta de valoración social de la formación artística, que incide en una escasa presencia curricular, que incide en una escasa atención y profesionalización de los educadores, que incide en la escasa formación de la sensibilidad artística que incide otra vez en la falta de valoración de la formación artística... y así hasta el infinito. Aguirre (2000:21)

Plantear nuevos enfoques en la educación artística pasa, inicialmente, por detectar de qué manera se produce actualmente esta enseñanza en las aulas de primaria, y por constatar que, en la gran mayoría de los casos, sigue estrechamente relacionada a métodos tradicionales. 
$2^{\text {nd }}$ International Conference Art, Illustration and Visual Culture in Infant and Primary Education de Arte, llustração e Cultura Visual

na Educação Infantil e Primária

En primer lugar, destacamos la ausencia de especialista de Educación Visual y Plástica en la etapa de primaria, lo que conlleva que sea el mismo maestro titular quién imparta su enseñanza. Se ha podido comprobar que este hecho provoca, entre muchos maestros de nuestro país, ciertas inseguridades profesionales, y perpetua entre ellos, una concepción de la "plástica", aun muy vinculada a las manualidades y la autoexpresión.

No olvidemos que en la titulación de grado de maestro en España, se propone normalmente una sola asignatura de Didáctica de la Educación Visual y Plástica en su currículum docente. Con esa formación previa, una vez titulados, los profesionales de la educación primaria deben impartir una media de 85 horas anuales de educación artística a sus alumnos.

Consideramos que un paso imprescindible para la mejora metodológica de la enseñanza artística es incentivar la formación permanente del profesorado de primaria hacia contenidos de esta área de conocimiento, la Educación Visual y Plástica, carente de especialización en España así como en gran parte de países europeos.

Para plantear esta iniciativa, la pregunta que creemos necesaria formular es ¿Qué tipo de educación queremos para los niños y niñas de hoy? y por tanto ¿De qué manera deseamos potenciar la educación artística en la escuela?

Enfocar la Educación Artística del siglo XXI, precisa, en nuestra opinión, de una enseñanza artística:

- Ligada al mundo de los niños y niñas de hoy, en donde la Cultura Visual adquiere un peso considerable.

- Que promueva la percepción y el uso reflexivo de la imagen.

- Que articule la exploración de contenidos diversos así como la interpretación y la creación de artefactos visuales, con el fin de "formar", mediante el arte y desde la crítica.

Asimismo consideramos esta área de aprendizaje como una plataforma excepcional para dotar a nuestros escolares de competencias en cuanto a la:

- Solución de problemas y la toma de decisiones (autonomía personal).

- Aplicación de conocimientos en diferentes contextos (funcionalidad de los aprendizajes, en una concepción interdisciplinar).

Para llevar a cabo dichas premisas en un contexto real, creemos conveniente optar por una metodología de aprendizaje compartido, potenciando el trabajo en grupo, en la línea de la investigación acción. Como ejemplos que sustentan el marco conceptual de nuestro estudio, mostraremos experiencias de aprendizaje llevadas a cabo entre futuros maestros de la Facultad de Formación del Profesorado de la Universidad de Barcelona desarrolladas por miembros del Departamento de Didàctica de l'Educació Visual i Plàstica para generar nuevas prácticas educativas. Dichas acciones educativas se centran en la adquisición de conceptos y procedimientos del lenguaje visual y plástico (eje vertebrador de programación), y se nutren asimismo de contenidos provenientes de otras disciplinas, tales como las ciencias naturales, las matemáticas, etc.

La particularidad de nuestra investigación se centra en demostrar que las propuestas que presentamos, dirigidas a la formación del profesorado de enseñanza superior son, del mismo modo, aplicables a entornos de enseñanza primaria.

\section{Formación de Profesorado.}

Las primeras observaciones a realizar de la formación de futuros maestros en las aulas universitarias, hacen referencia a los prejuicios y preconcepciones de los estudiantes de magisterio sobre la educación artística. Si bien algunos estudiantes muestran interés en la materia, la mayoría de ellos llegan a las aulas universitarias con muchas preconcepciones y prejuicios fruto de su propia formación en las etapas obligatorias de aprendizaje, todavía con fuertes vinculaciones a las manualidades y la autoexpresión. Por este motivo lo que nos proponemos poner en duda es la validez de éstas metodologías, utilizadas en el aprendizaje del arte, vigentes en las escuelas hasta ahora. Los argumentos para cuestionar ciertos modelos de 
2nd International Conference Art, Illustration and Visual Culture in Infant and Primary Education $2^{\circ}$ Congreso Internaciona

Arte, llustración y Cultura Visual en Educación Infantil y Primaria
Congresso Internacional

de Arte, Ilustração e Cultura Visual

na Educação Infantil e Primária

\subsection{La propuesta en las aulas} del Grado de Magisterio. aprendizaje, los podemos basar en la escasa relación de éstos métodos, con lo que conforma el mundo real de nuestros futuros alumnos, tanto los universitarios como los de primaria. Creemos que la educación en general y específicamente del arte, tiene, necesariamente, que extrapolarse al mundo que se van a encontrar los futuros maestros y también los niños y niñas, según Efland, Freedman y Stuhr: (...) la finalidad de la enseñanza del arte es contribuir a la comprensión del panorama social y cultural en el que viven todos los individuos. (2003:125)

Nosotros pensamos que el primer paso para romper ciertas inercias es trastocar los esquemas adquiridos por los estudiantes de magisterio para evitar su repetición.

Si bien los entendidos pueden defender que el aprendizaje del dibujo no es el único aprendizaje que puede realizar un alumno en clases de arte, partimos de una tradición (la Europea y occidental), en la que el aprendizaje del dibujo es su piedra angular, confundiéndose la formación artística con el aprendizaje del dibujo. Como apunta (Bamford, 2009:88): Muchos profesores generalistas tienen la sensación de que si no saben dibujar, tampoco pueden enseñar materias artísticas.

Ante esta situación, nuestro punto de partida fue, justamente, "atacar" con una propuesta" donde se relacionaba el dibujo con la anatomía y el trabajo en grupo. El "encargo" a los estudiantes consistió en dibujar a tamaño natural un cuerpo humano; la mitad sería el esqueleto y la otra mitad los músculos, también tenían que indicar los movimientos de las articulaciones (con sus nombres técnicos) y crear un código visual que mostrase la información de manera clara. Para su realización, se restringió el material para favorecer la concentración de los esfuerzos para con la actividad.

Inicialmente, el reto planteado, sobrepasó a los alumnos. El comentario más pronunciado fue que no lo podrían hacer. Y en este punto, es donde entra en juego la sinergia creada por el trabajo en grupo. Tímidamente empezaron a plantear cómo iniciar el proyecto, el diálogo entre los componentes del grupo fue el núcleo de la experiencia educativa. Diálogo en forma de discusiones que acompañaron todo el proceso de aprendizaje y creación; primero para interpretar las imágenes que tenían de referencia, después para plasmar esta información sobre el papel, también para resolver cómo formalizar el código visual.... El desacuerdo entre los componentes del grupo, el hecho de tener que explicar el punto de vista de cada uno de los integrantes del grupo y luego el acuerdo, el pacto y la construcción conjunta del esqueleto provocó la superación (con creces) de la propuesta.

Uno de los puntos interesantes que plantea la presente comunicación, es la relación entre la formación del profesorado y la repercusión que ésta tiene en nuestras escuelas. Lo que hemos querido comprobar con esta experiencia es hasta qué punto, una propuesta educativa, diseñada a priori para los alumnos universitarios, puede ser implementada por alumnos de primaria con resultados óptimos. La experiencia, muestra que, a pesar de que se sean precisas ciertas modificaciones relacionadas con la edad del alumnado o la metodología de enseñanza, tanto los contenidos basados en el saber transdisciplinar como los objetivos de aprendizaje no varían en absoluto, entre los alumnos universitarios y los de primaria.

Después de valorar la adecuación de la propuesta con el fin de hacerla extensible al contexto de primaria, se optó por implementarla con niños y niñas de $4^{\circ}$ y $5^{\circ}$ curso de primaria del Liceo Francés de Barcelona, un centro de enseñanza infantil, primaria y secundaria de titularidad pública, perteneciente al estado francés, durante el primer trimestre del presente curso académico, 2011-12. 
Para derivar dicha experiencia "de aula universitaria" a "aula de primaria", se tuvieron que realizar algunas adaptaciones didácticas. La primera diferencia que nos encontramos entre el grupo de estudiantes universitarios y el de primaria fue la cuestión de "conocimientos previos". Mientras que los universitarios poseían conocimientos bien precisos sobre anatomía humana, los alumnos de primaria los tenían tan solo vagamente.

Por esta razón, durante la secuencia didáctica, se impartieron inicialmente contenidos teóricos de las áreas de "Conocimiento del Medio Natural, social y cultural" y de "Matemáticas", concretamente aquellos que hacen referencia al cuerpo humano y a las escalas y proporciones, respectivamente 3 .

Además de conjugar la actividad plástica con aspectos relativos a las matemáticas y las ciencias naturales, se trabajó también, de forma indirecta, el aprendizaje de la lengua, el catalán (con la particularidad que para la mayoría de los alumnos se trata de una lengua extranjera), así como de la cultura artística (a partir de referentes clave del dibujo anatómico como Leonardo da Vinci, etc.).

La fase inicial del proyecto precisó, por tanto, de un trabajo previo interdisciplinar que ayudó a entrar con más garantías de éxito en la acción principal de la propuesta didáctica. La temporización también contempló sesiones guiadas de búsqueda de información especializada en el tema, a partir de libros, revistas, enciclopedias y de páginas web de internet.

La propuesta articuló de manera directa e indirecta la mayoría de competencias básicas que defiende el curriculum de primaria: la artística, la comunicativa, la digital, la de autonomia e iniciativa personal...

Otra especificidad de la propuesta en primaria fue la elaboración de un dibujo inicial sobre esqueleto humano, de manera individual. Durante esta fase se trabajaron aspectos referentes a la proporción del cuerpo humano. Los dibujos se realizaron en formato Din-A4 mientras que el proyecto final de grupo fue a escala real de un niño de la clase. Este cambio de escala nos permitió observar si los alumnos habían entendido los aspectos básicos de la proporción y reforzar los conceptos en los casos en los que se percibían ciertas dificultades.

En la realización del proyecto en gran formato, también se vieron diferencias. Mientras que en las aulas universitarias el encaje del dibujo se realizó mediante la silueta de uno/ de los/ as alumnos/as, en primaria utilizamos el concepto de proporción y el dibujo previo realizado de manera individual para garantizar que todos los niños/as entendieran e incorporasen éstos conocimientos.

La gestión del aula también fue sensiblemente distinta. Mientras que los futuros maestros se organizaban de manera más autónoma, la organización y dinámica de clase de primaria se vió necesitada de una presencia mucho más guiada por parte de la tutora. Por ejemplo, en la elaboración de la leyenda (código visual) de los huesos la tutora tuvo que estar pendiente de la correcta utilización y ubicación de los nombres en el conjunto del trabajo.

\section{Conclusión}

A continuación, nos disponemos a explicar las conclusiones de nuestra propuesta. En una primera parte, en referencia a la experiencia en la universidad, seguidamente en la etapa de primaria, y finalmente, unas reflexiones globales.

En lo referente a la propuesta en las aulas universitarias podemos decir que los estudiantes pudieron incorporar aprendizajes de distintas índoles gracias a la realización del proyecto.

En primer lugar se hizo un uso reflexivo, contrastado y crítico de las imágenes anatómicas. Los alumnos pudieron observar y sacar conclusiones sobre el uso de las imágenes, diferentes tipos de representación que nos porporcionan las imágenes (y contraposición con la realidad).

Se pusieron en juego también, conocimientos de diferentes áreas remarcando nuestro interés en la interdisciplinariedad en las aulas. No solamente basándonos en una disciplina concreta sino tratando de sobrepasarla, ir más allá y cuando sea posible difuminar las barreras disciplinares. 
$2^{\text {nd }}$ International Conference Art, Illustration and Visual Culture in Infant and Primary Education
${ }^{\circ}$ Congresso Internacional

de Arte, Ilustração e Cultura Visual

na Educação Infantil e Primária

Además se fomenta la autonomía, tanto la individual, pero sobretodo la de grupo, favoreciendo el diálogo, la toma de decisiones, así como la aplicación de conocimientos de diferentes contextos.

En la universidad, esta propuesta se realizó en la asignatura Didàctica de l'Educació Visual i Plàstica, pero no vemos, por que no, se podría proponer en otra àrea de conocimiento. Quizás en nuestro contexto, la experiencia pueda ser una muestra más de educación en las artes (con interés hacia la interdisciplinariedad) pero en otros contextos educativos, podríamos considerar el proyecto como una muestra de educación a través de las artes, sobre todo si tenemos en cuenta que los estudiantes universitarios serán, en la mayoría de los casos y en un futuro próximo, maestros generalistas. Desde este punto de vista, podríamos considerar que la experiencia presentada puede colaborar a incorporar enfoques transdisciplinarios, competenciales y creativos en las aulas de primaria.

En lo referente a la propuesta en las aulas de primaria, podemos afirmar que la actividad propuesta en las aulas universitarias es extrapolable a las aulas de ésta etapa educativa. Es evidente que con una adaptación didáctica aplicable a primaria, los alumnos pueden alcanzar los objetivos del trabajo y consideramos que la dinámica de clase propuesta favorece a su adquisición.

Los niños y niñas pudieron incorporar distintos tipos de aprendizajes gracias al análisis de las imágenes:

- Búsqueda y formación de un criterio para escoger un tipo de imagen anatómica u otra.

- Observación e interpretación de las imágenes.

- Traducción gráfica de la información-conocimiento adquirido-aprendido.

Podemos destacar que, a pesar de la complejidad de la gestión de aula por parte de los/ as maestros/as, este tipo de propuestas dotan al alumnado de una visión más global e interdisciplinar en el marco de la escuela, donde los saberes, a pesar de la inclusión de las competencias, están todavía muy parcelados. Este proyecto no pone en juego, solamente, el factor contenidos, sino que deja translucir una filosofía educativa que defiende que la formación no consiste exclusivamente en dotar de contenidos, formar también es dar herramientas para poder alcanzar los retos que éste (y otros) proyectos puedan suponer para la la formación global en la etapa de primaria.

Iniciamos esta comunicación enunciando una serie de objetivos que nos proponíamos para iniciar un cambio en la formación de los futuros maestros, y por consiguiente, en el enfoque que se da de la Educación Visual y Plástica en las aulas de primaria. Podemos concluir al respecto diciendo que nuestra propuesta, tanto en las aulas universitarias como en primaria:

- Está ligada a la Cultura Visual, en lo referente a la búsqueda, gestión, observación y análisis de las imágenes.

- Articula la inclusión de contenidos de diversos ámbitos, creando una interrelación más allá de una asignatura concreta.

- Propone un trabajo artístico como núcleo para el aprendizaje.

- La organización y secuencia favorece el desarrollo tanto de la autonomía personal, como la de grupo destacando el desarrolo de la toma de decisiones conjunta.

\section{Referencias bibliográficas}

Aguirre, I. (2000). Teorías y Prácticas en Educación Artística. Pamplona: Universidad Pública de Navarra.

Bamford, A. (2009) El efecto ¡wuau! El papel de las artes en la educación. Barcelona: Octaedro.

Efland, A.D., Freedman, K., Stuhr, P. (2003) La educación en el arte postmoderno. Barcelona: Paidós 
2nd International Conference Art, lllustration and Visual Culture in Infant and Primary Education $2^{\circ}$ Congreso Internacional Arte, Ilustración y Cultura Visual en Educación Infantil y Primaria $2^{\circ}$ Congresso Internacional

de Arte, llustração e Cultura Visual na Educação Infantil e Primária

Portal del Departament d'Educació de la Generalitat de Catalunya. Edu365.cat. El cos humà 2.o. [en línea] [Consulta: 31 de Octubre 2012] Disponible en <http://www.edu365.cat/aulanet/coshumà/>.

Portal del Departament d'Educació de la Generalitat de Catalunya. Edu365.cat. L'esquelet.[en línea] [Consulta: 7 de Noviembre 2012] Disponible en <http://www.edu365.cat/primaria/muds/natural/ esquelet>

Spongelab. Build a body. [en línea] [Consulta: 14 de Noviembre 2012] Disponible en <http://www.spongelab. com/interactives/buildabody/en/whole/index.html> 